\title{
Somatostatin receptor subtype expression in cells of the rat immune system during adjuvant arthritis
}

\author{
A M C ten Bokum ${ }^{1}$, E G R Lichtenauer-Kaligis ${ }^{2}$, M J Melief ${ }^{1}$, \\ P M van Koetsveld ${ }^{2}$, C Bruns ${ }^{3}$, P M van Hagen ${ }^{1,2}$, L J Hofland ${ }^{2}$, \\ S W J Lamberts ${ }^{2}$ and $M$ P Hazenberg ${ }^{1}$ \\ ${ }^{1}$ Department of Immunology, Erasmus University, PO Box 1738, 3000 DR Rotterdam, The Netherlands \\ ${ }^{2}$ Department of Internal Medicine III, University Hospital Dijkzigt, Dr Molewaterplein 40, 3015 GD Rotterdam, The Netherlands \\ ${ }^{3}$ Novartis Pharma AG, 4002 Basel, Switzerland \\ (Requests for offprints should be addressed to A M C ten Bokum)
}

\begin{abstract}
Somatostatin is a neuropeptide that is widely distributed throughout the body. It acts as a neurohormone and a neurotransmitter and may also have an immunomodulatory role. The genes for five subtypes of somatostatin receptors (sst) have been cloned, suggesting that the diverse effects of the peptide might be mediated by different receptors.

We are interested in studying the role of sst in inflammation, using an animal model. Because of the up-regulation of sst expression in inflamed joints in human rheumatoid arthritis, we chose rat adjuvant arthritis as an experimental model. In order to determine which of the sst subtypes might be important in immune modulation, subtype expression in leukocytes isolated from different lymphoid tissues of the rat was studied. Also, the expression levels of the most abundantly expressed sst mRNAs in leukocytes from spleen and blood were compared in rats with adjuvant arthritis and controls, using a semi-quantitative approach. Furthermore, the effect of systemic administration of a long-acting somatostatin analogue, octreotide, which binds selectively to sst subtypes 2 and 5 (sst ${ }_{2}$ and $\mathrm{sst}_{5}$ ), on the incidence and the severity of rat adjuvant arthritis, was studied.
\end{abstract}

The main sst expressed in cells of the rat immune system, both resting and activated, were found to be $\mathrm{sst}_{3}$ and sst $_{4}$. This contrasts with the human and murine situations, in which $s_{2} t_{2}$ appears to be the main subtype expressed in the immune system. No quantitative differences in sst subtype mRNA levels in leukocytes from spleen and blood were found between rats with adjuvant arthritis and controls. Finally, no effect of systemic administration of octreotide on either the incidence or severity of adjuvant arthritis in Lewis rats was found. As octreotide binds selectively to $s_{2} t_{2}$ and $s_{5} t_{5}$, the absence of an immunomodulatory effect of this analogue in rat adjuvant arthritis corroborates our finding that these sst subtypes are not expressed in cells of the rat immune system. In conclusion, cells of the rat immune system appear to express a spectrum of sst (sst ${ }_{3}$ and sst $_{4}$ ) different from that found in human granulomatous and autoimmune disease (mainly sst ${ }_{2}$ ). Therefore, the rat adjuvant arthritis model appears to be suitable only for studying the immunomodulatory effects of somatostatin analogues which have a high affinity for $s t_{3}$ and $s_{4} t_{4}$, but not for studying the immunomodulatory effects of octreotide, which has a high affinity only for $\mathrm{sst}_{2}$ and $\mathrm{sst}_{5}$.

Journal of Endocrinology (1999) 161, 167-175

\section{Introduction}

Somatostatin is a neuropeptide that is widely distributed throughout the body. It was first identified as a growth hormone release-inhibiting factor synthesised in the hypothalamus. Outside the central nervous system, the peptide is present in a variety of endocrine and nonendocrine tissues, and it appears to have many functions. In the central nervous system it can act as a neurotransmitter and neurohormone, while in peripheral tissues it regulates endocrine and exocrine secretion and acts as a modulator of motor activity in the gastrointestinal tract (Reichlin 1983, Brazeau 1986). There is also increasing evidence that somatostatin can have immunomodulatory actions (for a review see Van Hagen et al. (1994a)). Specific receptors (sst) for somatostatin have been identified in lymphoid tissues and on the surface of various white blood cells and cell lines by classic ligand-binding studies (Van Hagen et al. 1994a). In addition it was found, in a number of granulomatous (i.e. sarcoidosis) and autoimmune diseases (i.e. Graves' ophthalmopathy and rheumatoid arthritis), that sites of active inflammation 
could be visualised after the administration of an isotopecoupled somatostatin analogue (Van Hagen et al. 1994b,c).

Since we are interested in studying the role of sst in such inflammatory diseases, we decided to use an animal model. Because of the up-regulation of sst expression in inflamed joints in human rheumatoid arthritis (Reubi et al. 1994, Van Hagen et al. 1994c), we specifically chose rat adjuvant arthritis as an experimental model (for a review, see Wauben et al. (1994)). The low numbers of leukocytes that can be obtained from the joints of rats with adjuvant arthritis prohibit analysis of the sst subtypes expressed by these cells. However, as adjuvant arthritis is considered to be a systemic disease in which the causative agent disseminates throughout the tissues of the body (Van Arman 1976, Vernon-Roberts et al. 1976, Kleinau et al. 1995), an experimental approach was set up to study the sst subtype expression in leukocytes isolated from lymphoid organs and peripheral blood of rats with adjuvant arthritis and controls. We also made a comparison of the expression levels of the most abundantly expressed sst mRNAs in leukocytes from spleen and blood of rats with adjuvant arthritis and controls, using a semi-quantitative approach. Furthermore, we studied the effect of systemic administration of a long-acting somatostatin analogue, octreotide, which binds specifically to sst subtypes 2 and 5 (sst ${ }_{2}$ and sst $_{5}$ ), on the incidence and the severity of rat adjuvant arthritis, as somatostatin has been shown to have beneficial effects in human rheumatoid arthritis (Coari et al. 1995).

\section{Materials and Methods}

\section{Animals}

Female Lewis rats (Harlan Sprague-Dawley, Bicester, UK), 7-8 weeks of age, were used. The animals were kept under clean conventional conditions with free access to pelleted food and water in the animal facilities of the Department of Immunology. The experimental protocol was approved by the Animal Welfare Committee of Erasmus University.

\section{Induction of adjuvant arthritis}

In order to induce adjuvant arthritis, rats were injected i.d. in the base of the tail with $1 \mathrm{mg}$ of a suspension of heat-killed Mycobacterium tuberculosis strain H37 RA (Difco Laboratories, Detroit, MI, USA) in incomplete Freund's adjuvant (IFA) (Difco), prepared by grinding in a mortar, as described by Wauben et al. (1994). This preparation will be further referred to as complete Freund's adjuvant (CFA). Control rats were injected with IFA only.

\section{Preparation of cell suspensions}

In order to study the sst subtype expression in rats in an inflammatory versus a non-inflammatory state, adjuvant arthritis was induced in ten rats, as described above. Ten control rats were injected with IFA only. The rats were killed by decapitation 3 weeks after injection, at peak inflammation. Cell suspensions were prepared as described below for analysis by reverse transcription polymerase chain reaction (RT-PCR).

Peripheral blood Peripheral blood was collected in polypropylene tubes containing $100 \mathrm{IE}$ heparin (Leo Pharmaceutical Products BV, Weesp, The Netherlands). Peripheral blood mononuclear cells (PBMC) were purified by density centrifugation on Ficoll-Paque, density= $1.077 \mathrm{~kg} / 1$ (Pharmacia, Uppsala, Sweden). PBMC from rats within one experimental group were pooled.

Lymphoid organ cell suspensions Spleen, thymus and peripheral lymph nodes (popliteal, inguinal and axillary nodes) were removed from the animals and cell suspensions were prepared in RPMI 1640 medium (Gibco BRL, Grand Island, NY, USA) supplemented with 10\% fetal calf serum (FCS) by pressing the organs through nylon gauze (mesh size $100 \mu \mathrm{m}$ ).

Erythrocytes were depleted from the spleen cell suspension by hypotonic lysis in a $10 \mathrm{mM} \mathrm{KHCO}_{3}$ buffer (pH 7.4) supplemented with $155 \mathrm{mM} \mathrm{NH}_{4} \mathrm{Cl}$ and $100 \mathrm{mM}$ EDTA ( $3 \mathrm{ml}$ per spleen). After $3 \mathrm{~min}$ at $4{ }^{\circ} \mathrm{C}$, the cells were washed twice in RPMI 1640 medium with 10\% FCS. Half of the total lymph node suspension was used to prepare a non-adherent cell fraction by passage over nylon wool (Leuko-Pak, Fenwall Laboratories, Deerfield, IL, USA).

The different cell populations were pooled per experimental group. The cells were washed in ice-cold PBS, pelleted and stored as dry pellets at $-80{ }^{\circ} \mathrm{C}$.

\section{$R N A$ isolation and $c D N A$ reaction}

PolyA $^{+}$mRNA was isolated from the cells using paramagnetic oligo(dT) beads (Dynabeads Oligo $(\mathrm{dT})_{25}$, Dynal AS, Oslo, Norway) according to the manufacturer's instructions. The polyA ${ }^{+}$mRNA was eluted in $30 \mu \mathrm{l}$ diethyl pyrocarbonate-treated water. All mRNA preparations were treated with deoxyribonuclease I (Amplification Grade, Gibco) for $15 \mathrm{~min}$ at room temperature in the buffer provided with the enzyme. The reaction was stopped by the addition of $2.5 \mathrm{mM}$ EDTA followed by heating at $65^{\circ} \mathrm{C}$ for $10 \mathrm{~min}$.

mRNA was extracted from $10^{7}$ cells in the case of mixed cell populations (spleen, thymus, total lymph node cells) and $2 \times 10^{6}$ cells in the case of more purified cell populations (PBMC and lymph node non-adherent cells).

Complementary DNA (cDNA) synthesis was performed starting with one-third of the isolated mRNA. Random hexamer primers were used to ensure that all RNA was represented equally in the cDNA pool (Tan \& Weis 1992). The reaction mixture contained $50 \mathrm{mM}$ 
Tris- $\mathrm{HCl}$ buffer, $\mathrm{pH} 8 \cdot 3,10 \mathrm{mM} \mathrm{MgCl}_{2}, 50 \mathrm{mM} \mathrm{KCl}$, $1 \mathrm{mM}$ dithiothreitol, $1 \mathrm{mM}$ EDTA, $10 \mu \mathrm{g} / \mathrm{ml}$ BSA, $1 \mathrm{mM}$ salmon spermine $\mathrm{HCl}$ (Sigma Chemical Co., St Louis, MO, USA), $1 \mathrm{mM}$ of each of the four deoxynucleotide triphosphates (DNA Polymerisation Mix, Pharmacia), $20 \mathrm{U}$ of RNA Guard (Pharmacia), 0.02 optical density units $(\mathrm{dN})_{6}$ (Pharmacia), $0 \cdot 2 \mu \mathrm{g}$ oligo $(\mathrm{dT})_{12-18}$ (Boehringer Mannheim, Mannheim, Germany) and $5 \mathrm{U}$ reverse transcriptase (from avian myeloblastoma virus; Promega, Madison, WI, USA) in a total reaction volume of $20 \mu$ l. The reaction mixture was incubated at $41^{\circ} \mathrm{C}$ for $1 \mathrm{~h}$ and the reaction was stopped by heating at $75^{\circ} \mathrm{C}$ for $10 \mathrm{~min}$. Each cDNA reaction was carried out in duplicate.

\section{Controls}

To ascertain that no genomic DNA was present in the polyA ${ }^{+}$preparations (which would give false-positive signals upon amplification, as sst genes do not contain introns), the cDNA reactions were also performed once without reverse transcriptase (negative control samples). These negative control samples never yielded positive signals on amplification.

cDNA from the GH3 rat pituitary cell line was used as a positive control for $\mathrm{sst}_{1}$ mRNA expression and cDNA from the transplantable prolactin-secreting rat pituitary tumour $7315 b$ as a positive control for sst $_{2}$ mRNA expression (Visser-Wisselaar et al. 1997). Rat genomic DNA, isolated by lysis of rat splenocytes in PCR buffer, was used as a positive control in the PCR reactions for sst $_{3-5}$.

The PCR reactions were optimised to detect at least $10^{4}$ copies of the sequence of interest (corresponding to $0 \cdot 1 \mu \mathrm{g}$ genomic DNA) in ethidium bromide-stained gels. If, in a particular series of PCR reactions, $10^{4}$ copies of genomic DNA after amplification did not give a clear signal in ethidium bromide-stained gel, the series was discarded.

\section{PCR}

One-tenth of the synthesised cDNA was used for each PCR reaction. The reaction mixture consisted of $10 \mathrm{mM}$ Tris- $\mathrm{HCl}$ buffer, $\mathrm{pH} 9 \cdot 0,50 \mathrm{mM} \mathrm{KCl}, 1.5 \mathrm{mM} \mathrm{MgCl}$, $0 \cdot 01 \%(\mathrm{w} / \mathrm{v})$ gelatine, $0 \cdot 1 \%(\mathrm{v} / \mathrm{v})$ Triton X-100, 0.05 mM of each of the four deoxynucleotide triphosphates (DNA Polymerisation Mix; Pharmacia), 5 pmol each of the forward and reverse primers specific for one of the five rat sst subtypes or for the $\beta$-actin gene, and $1 \mathrm{U}$ AmpliTaq DNA polymerase (Perkin-Elmer-Cetus, Norwalk, CT, USA). PCR reactions for all primer pairs were performed with each of the duplicate cDNA samples and positive and negative control samples.

The primers specific for the human $\mathrm{sst}_{1}$ and $\mathrm{sst}_{2}$ as described by Wulfsen et al. (1993) and for sst $_{3-5}$ as described by Kubota et al. (1994), were modified by us to match the rat sequences (Meyerhof et al. 1991, 1992,
Bruno et al. 1992, Kluxen et al. 1992, Li et al. 1992, Yasuda et al. 1992). The rat $\beta$-actin primers were as described by Vidal et al. (1994). sst ${ }_{1}$ forward 5'-ATGGTG GCCCTCAAGGCCGG-3', reverse 5'-GGCAGTGGC GTAGTAGTCAA-3' (product size $318 \mathrm{bp}$ ); sst $_{2}$ forward 5'-TCCTCTGGGATCCGAGTGGG-3', reverse 5'-TT GTCCTGCTTACTGTCGCT-3' (product size 332 bp); sst $_{3}$ forward 5'-TGCCAGTGGGTACAGGCACC-3', reverse 5'-CTGGAGGGCCAGACCCTGGC-3' (product size $328 \mathrm{bp}$ ); sst $_{4}$ forward 5'-TGCGGGCTGGCTGG CAACAA-3', reverse $5^{\prime}$-GTAGTCCAGGGGCTCTT CCT-3' (product size $311 \mathrm{bp}$ ); sst $_{5}$ forward $5^{\prime}$-AGCCT TCATCACCTACACGT-3', reverse 5'-GGCCAGGT TGACGATGTTGA-3' (product size $226 \mathrm{bp}$ ); $\beta$-actin forward 5'-TCATGCCATCCTGCGTCTGGACCT-3', reverse $5^{\prime}$-CCGGACTCATCGTACTCCTGCTTG-3' (product size $582 \mathrm{bp}$ ).

The reactions were carried out in a DNA thermal cycler (Perkin-Elmer-Cetus). After an initial denaturation for 5 min at $94{ }^{\circ} \mathrm{C}$, the samples were subjected to 35 cycles ( $\beta$-actin) or 40 cycles (sst subtypes) of denaturation at $94^{\circ} \mathrm{C}$ for $1 \mathrm{~min}$, annealing at $59^{\circ} \mathrm{C}\left(\beta\right.$-actin and sst $\left.{ }_{1-4}\right)$ or $55^{\circ} \mathrm{C}\left(\right.$ sst $\left._{5}\right)$ for $2 \mathrm{~min}$ and extension at $72{ }^{\circ} \mathrm{C}$ for $1 \mathrm{~min}$. These numbers of cycles had previously been shown to lie within the linear range of the reaction. After a final extension phase of $10 \mathrm{~min}$ at $72{ }^{\circ} \mathrm{C}, 40 \mu \mathrm{l}$ aliquots of the amplified products were analysed on $2 \%$ agarose gels stained with ethidium bromide. Weak bands were confirmed by hybridising Southern blots of the PCR products with subtype-specific oligonucleotide probes.

For semi-quantitative comparison of the amount of mRNA, a limiting dilution RT-PCR method was used (Kincy-Cain \& Bost 1997). Briefly, 2-fold serial dilutions of the cDNA preparations were normalised to give approximately equal $\beta$-actin signals, before performing PCR for the sst subtypes. The linearity of the dilution series was assessed by scanning the photographs of the ethidium bromide-stained gels and determining the intensity of the bands (Koning et al. 1995). For the most accurate quantification, care was taken to include a dilution of which the $\beta$-actin signal was no longer visible when analysed on ethidium bromide-stained gel. Comparisons were based on this dilution and the two preceding it.

\section{Receptor saturation curves}

The radioligands used in the binding studies were $\left[{ }^{125} \mathrm{I}_{-} \mathrm{Tyr}^{3}\right]$-octreotide and $\left[{ }^{125} \mathrm{I}_{-} \mathrm{Tyr}^{0}\right]$-somatostatin-28. $\left[\mathrm{Tyr}^{3}\right]$-octreotide was iodinated and HPLC purified as described previously (Bakker et al. 1990). [ ${ }^{125}{\left.\mathrm{I}-\mathrm{Tyr}^{0}\right]-}_{-}$ somatostatin-28 was purchased from ARC-Biotrend (Cologne, Germany). Reaction conditions were the same as described by Reubi (1985). Briefly, cell membrane preparations (corresponding to $15-30 \mu \mathrm{g}$ protein) were incubated at room temperature for $60 \mathrm{~min}$ with increasing 
concentrations of radioligand in a total volume of $100 \mu \mathrm{l}$ Hepes buffer $\left(10 \mathrm{mM}\right.$ Hepes, $5 \mathrm{mM} \mathrm{MgCl}_{2}$ and $0 \cdot 2 \mathrm{~g} / 1$ bacitracin, $\mathrm{pH} 7 \cdot 6)$ containing $0 \cdot 2 \%(\mathrm{w} / \mathrm{v}) \mathrm{BSA}$. After the incubation, $1 \mathrm{ml}$ ice-cold Hepes buffer was added to the assay mixture and membrane-bound radioactivity was separated from unbound activity by centrifugation ( $2 \mathrm{~min}$ $10000 \boldsymbol{g}$ in an Eppendorf centrifuge). The remaining pellet was washed twice with ice-cold Hepes buffer and radioactivity remaining in the final pellet was counted in a gamma counter. Specific binding was taken to be the total bound activity minus the activity bound in the presence of $1 \mu \mathrm{M}$ unlabelled octreotide (Sandostatin; Novartis Pharma, Basel, Switzerland) or somatostatin-28 (Bachem, Bubendorf, Switzerland) respectively. As a positive control for binding, cell membranes from the mouse pituitary cell line AtT20 were included in each test.

\section{Systemic administration of octreotide and monitoring of arthritis}

The effect of systemic administration of octreotide, a long-acting somatostatin analogue, on adjuvant arthritis in the rat was studied. Sandostatin-LAR, a slow-release formulation of octreotide, was used. This formulation gives a continuous release of octreotide for a period of 6 weeks after s.c. injection.

One day prior to the induction of arthritis, ten rats were injected s.c. in the dorsal neck region with a suspension of Sandostatin-LAR (a gift from Novartis Pharma) in standard injection vehicle (buffered sodium carboxylmethylcellulose), corresponding to 10 (experiments 1 and 2) or $30 \mathrm{mg} / \mathrm{kg}$ octreotide (experiment 3 ). Ten control rats were injected with standard injection vehicle only. The next day adjuvant arthritis was induced in all the rats as described above. Disease course was monitored twice weekly for 6 weeks by measuring the diameter of all four paws using industrial callipers. The animals were weighed once a week and their general appearance and behaviour were monitored to assess their condition. Blood was collected by orbital puncture on days 21 and 42 of the experiment. The rats were killed by $\mathrm{CO}_{2}$ asphyxiation on day 42 .

\section{Results}

With a view to using rat adjuvant arthritis as an animal model in which to study the role of sst in inflammation, we determined the expression pattern of the five known sst subtypes in the major lymphoid organs of the rat, using RT-PCR.

In order to study mainly leukocytes, stromal components were removed from the lymphoid organs under study by passing them through nylon gauze. Other authors have studied only whole organs of the rat (Bruno et al. 1993, Raulf et al. 1994).
Table 1 Sst subtype mRNAs in cells of the rat immune system: summary of RT-PCR study

\section{Source of leukocytes}

Spleen

Peripheral blood

Thymus

Lymph nodes

Lymph nodes (non-adherent cells)

+ , visible on ethidium bromide-stained agarose gel; \pm , not visible, bu visualised by Southern blotting.

The results of the RT-PCR studies are shown in Table 1. The major sst subtypes expressed in rat leukocytes were found to be $s_{3}$ and $s_{3}$. A very weak sst $t_{1}$ signal was observed in spleen cells in some, but not all, experiments. No expression of sst $_{2}$ or sst $_{5}$ was observed in any of the cell populations, even after a repeat amplification. A ladder pattern of amplification products was consistently observed in the sst $_{4}$ PCR of thymocytes, but hybridisation of a Southern blot of the PCR gel with an sst $_{4}$-specific probe yielded only a single band of the expected size. The sst $_{4}$-specific band for the total lymph node and lymph node non-adherent cell preparations was barely visible in the ethidium bromide-stained gel, but could be visualised by Southern blot hybridisation with an sst $_{4}$-specific probe. The pattern of expression of sst in rat leukocytes was confirmed in splenocytes from other strains of rats (females: Wistar, Brown Norway, Wag/Rij, Sprague-Dawley, Buffalo and Fisher F344). Again only sst $_{3}$ and sst $_{4}$ were expressed, with occasionally a very weak sst, ${ }_{1}$ signal (not shown).

\section{Receptor saturation curves}

Receptor saturation experiments were carried out on membrane preparations of splenocytes and thymocytes of control Lewis rats using the radioligands $\left[{ }^{125} \mathrm{I}_{-} \mathrm{Tyr}^{0}\right]-$ somatostatin-28 and $\left[{ }^{125} \mathrm{I}_{-} \mathrm{Tyr}^{3}\right]$-octreotide. $K_{\mathrm{d}}$ values and receptor densities were determined by Scatchard analysis of the saturation curves.

No membrane binding of $\left[{ }^{125} \mathrm{I}_{-} \mathrm{Tyr}^{3}\right]$-octreotide was found (not shown), but $\left[{ }^{125} \mathrm{I}-\mathrm{Tyr}^{0}\right]$-somatostatin-28 bound with a $K_{\mathrm{d}}$ of 0.5 and $0.3 \mathrm{nM}$ for splenocytes and thymocytes respectively. As a control for binding, sst-positive AtT20 mouse pituitary tumour cells were used $\left(K_{\mathrm{d}}=0.9 \mathrm{nM}\right)$. The calculated numbers of binding sites were 755,492 and $2679 \mathrm{fmol} / \mathrm{mg}$ protein for splenocytes, thymocytes and AtT20 cells respectively. Figure 1 shows the Scatchard plots for the binding of $\left[{ }^{125}{\left.\mathrm{I}-\mathrm{Tyr}^{0}\right]-}_{-}\right.$ somatostatin-28.

\section{Semi-quantitative comparison of sst $_{3}$ expression}

Limiting dilution RT-PCR was performed to semiquantitatively compare $s t_{3}$ mRNA levels in splenocytes 


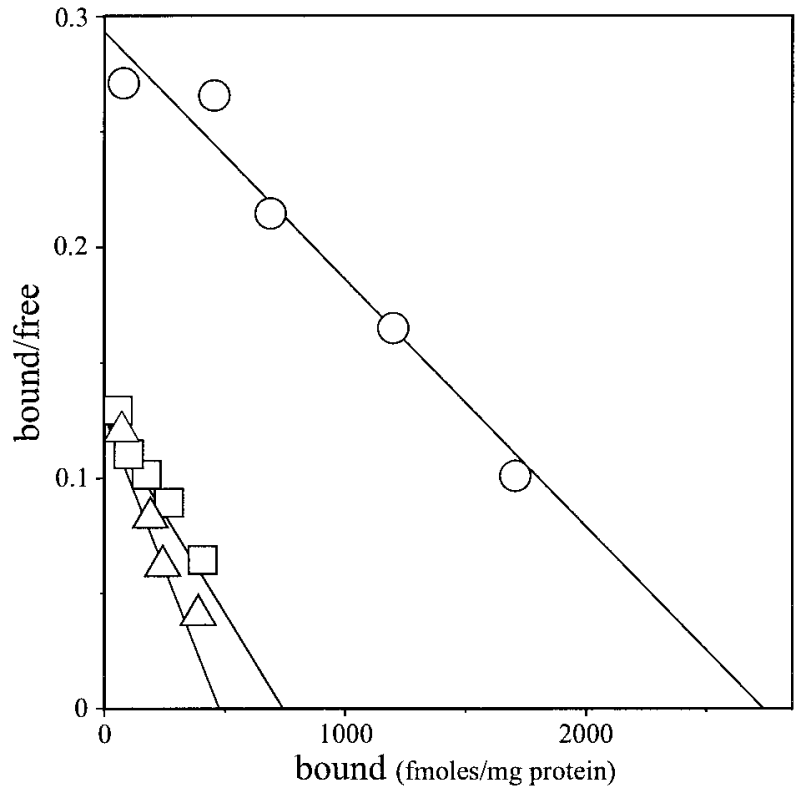

Figure 1 Sst expression at the protein level in rat splenocytes and thymocytes. Scatchard analysis of $\left[{ }^{125}{ }^{1}-\mathrm{Tyr}^{0}\right]$-somatostatin-28 binding to Lewis rat splenocytes and thymocytes and the sst-positive mouse pituitary tumour cell line, AtT20. $\bigcirc$ AtT20 cells $\left(K_{\mathrm{d}}=0.9 \mathrm{nM}, n=2679 \mathrm{fmol} / \mathrm{mg}\right), \square$ Lewis splenocytes $\left(K_{\mathrm{d}}=0.5 \mathrm{nM}\right.$, $n=755 \mathrm{fmol} / \mathrm{mg}), \triangle$ Lewis thymocytes $\left(K_{\mathrm{d}}=0.3 \mathrm{nM}\right.$, $n=492 \mathrm{fmol} / \mathrm{mg}$ ).

from CFA-injected rats with adjuvant arthritis (further referred to as CFA-injected rats) and controls. Two-fold serial dilutions of cDNA were titrated to give approximately equal $\beta$-actin signals and were then subjected to PCR for sst $_{3}$. The results are shown in Fig. 2. No substantial differences in the amount of sst $_{3}$ mRNA in CFA-injected versus control rats could be demonstrated.

\section{Differential expression of $s_{4} t_{4} m R A$ in leukocyte subpopulations}

$\mathrm{Sst}_{4}$ was expressed at levels readily detectable on ethidium bromide-stained gels only in splenocytes and peripheral blood, whereas expression in the other lymphoid cell preparations was only detectable after Southern blotting. This was true for both CFA-injected rats and control rats. Peripheral blood and spleen, as well as peripheral lymph nodes harbour large numbers of activated cells during systemic inflammation. However, spleen and peripheral blood contain a relatively larger proportion of monocytes in addition to their lymphocytes. The difference observed in sst $_{4}$ expression levels between peripheral blood and splenocytes on the one hand and lymph nodes on the other hand, suggested that sst $_{4}$ might be expressed by monocytes and cells of the monocyte lineage such as dendritic cells. A cell population enriched for dendritic cells, isolated from the spleen of a normal Lewis rat, was found to express sst ${ }_{4}$
mRNA (not shown). We therefore set out to prepare, from peripheral blood, a cell population enriched for monocytes, using density centrifugation over Percoll. Sst ${ }_{3}$ and sst $_{4}$ were expressed in the unseparated population and also in both populations obtained after density centrifugation (not shown). The cellular composition of the different populations is summarised in Table 2 .

Limiting dilution RT-PCR was carried out as described above to semi-quantitatively compare the sst $_{4}$ mRNA expression in the different populations. The results are shown in Fig. 3. It was shown that the interphase cell population had a relatively higher sst $_{4}$ expression than either the pellet population or total PBMCs. This was true for both CFA-injected and control rats.

\section{The effect of systemic administration of octreotide on adjuvant arthritis}

We studied the effect of systemic administration of octreotide on the incidence and the severity of rat adjuvant arthritis, as somatostatin has been shown to have beneficial effects in human rheumatoid arthritis (Coari et al. 1995). Sandostatin-LAR was used in three separate experiments (see Table 3). The data show that neither a low dose $(10 \mathrm{mg} / \mathrm{kg})$ nor a higher dose $(30 \mathrm{mg} / \mathrm{kg})$ of SandostatinLAR had an effect on incidence and severity of the arthritis.

Arthritis was confirmed histologically. Marginal erosion of the bone and hyperplastic synovium extending into the joint cavity was observed, with an infiltrate consisting mainly of lymphocytes, polymorphonuclear cells and histiocytes.

In the first experiment the octreotide levels in the serum were determined on days 21 and 42. The mean concentrations \pm S.E.M. were $2 \cdot 353 \pm 0.641$ and $1.524 \pm$ $0.744 \mathrm{ng} / \mathrm{ml}$ respectively for the octreotide-treated group, and undetectable $(<0.1 \mathrm{mg} / \mathrm{ml})$ for the control group. Nine rats out of ten still had detectable serum levels of octreotide on day 42. These data show that the octreotide was released from the s.c. depot continuously throughout the course of the experiment.

\section{Discussion}

Somatostatin is a ubiquitous neuropeptide with diverse physiological functions. The recent cloning of a family of sst and the demonstration that these receptors differ in their affinities for synthetic somatostatin analogues (Shimon et al. 1997) suggest that the diverse actions of somatostatin might be mediated by different receptor subtypes.

We are interested in the immunomodulatory effects of somatostatin and somatostatin analogues. Because of the up-regulation of sst expression in inflamed joints in human rheumatoid arthritis, we chose rat adjuvant arthritis as an 


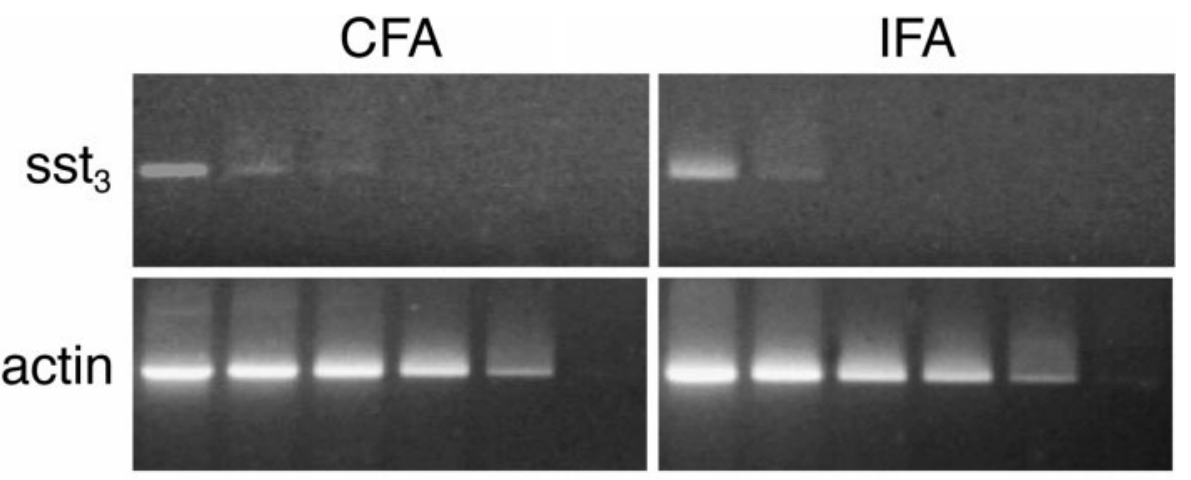

Figure $2 \mathrm{Sst}_{3}$ mRNA expression levels in rats with adjuvant arthritis and controls. For semi-quantitative comparison of $\mathrm{sst}_{3}$ mRNA expression in splenocytes of Lewis rats with adjuvant arthritis (CFA-injected) versus controls (IFA-injected), serial 2 -fold dilutions of cDNA were subjected to PCR for $\beta$-actin and sst $_{3}$.

CFA

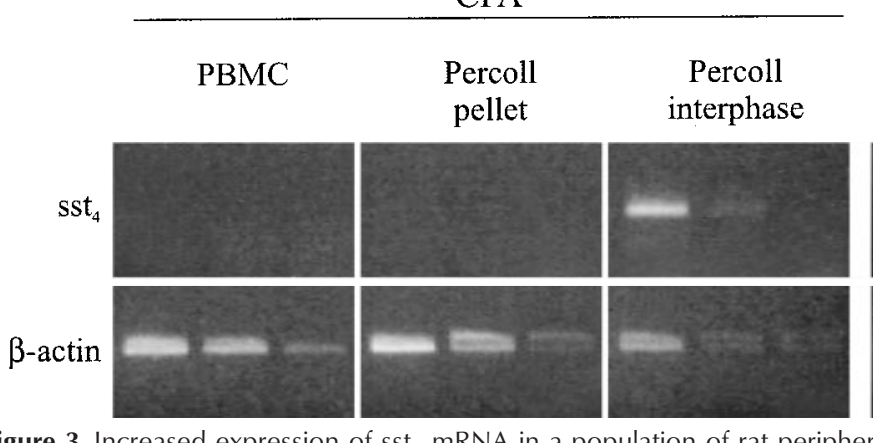

IFA

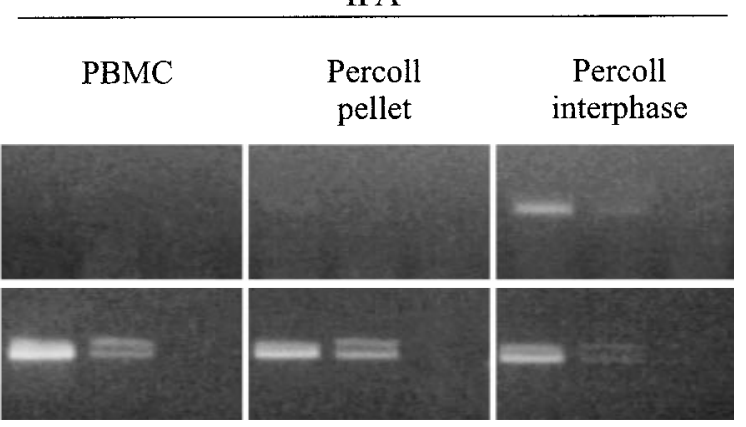

Figure 3 Increased expression of sst 4 mRNA in a population of rat peripheral blood cells enriched for monocytes. Subpopulations of PBMC from Lewis rats with adjuvant arthritis (CFA injected) and controls (IFA injected) were prepared by density centrifugation over Percoll. For semi-quantitative comparison of sst $_{4}$ mRNA expression levels, serial 2-fold dilutions of cDNA were subjected to PCR for $\beta$-actin and sst $_{4}$. The cDNA samples in the $\beta$-actin panel of the figure are diluted 8 -fold as compared with the corresponding samples in the sst $_{4}$ panel.

Table 2 Cellular composition (\%) by nuclear morphology of the peripheral blood cell populations before and after Percoll density centrifugation

\begin{tabular}{|c|c|c|c|c|c|c|}
\hline & \multicolumn{3}{|l|}{ CFA } & \multicolumn{3}{|l|}{ IFA } \\
\hline & PMN & Lymphocyte & Monocyte & $\mathrm{PMN}$ & Lymphocyte & Monocyte \\
\hline PBMC & 7 & 91 & 2 & 12 & 80 & 8 \\
\hline Percoll pellet & 9 & 85 & 5 & 2 & 90 & 8 \\
\hline Percoll interphase & 4 & 78 & 18 & 4 & 80 & 16 \\
\hline
\end{tabular}

PMN, polymorphonuclear.

experimental model. In order to determine which of the sst subtypes might be important in immune modulation, we studied the sst subtype expression in lymphoid tissues and cells of the rat, using RT-PCR.

The main sst expressed in cells of the rat immune system, both resting and activated, were found to be $\mathrm{sst}_{3}$ and $s_{4} t_{4}$. This contrasts with the situation in humans and mice, in which $s_{2} t_{2}$ appears to be the main subtype expressed in the immune system (Elliott et al. 1994, Van Hagen et al. $1994 a$ and unpublished observations).

Furthermore, our results indicate that $\mathrm{sst}_{4}$ is expressed by distinct sub-populations of rat leukocytes. A peripheral blood cell fraction enriched for monocytes showed an increased sst $_{4}$ expression. However, we were not able to obtain a highly purified rat monocyte population using density centrifugation. Flow cytometric analysis suggests that, in contrast to what is seen in humans, rat PBMC exhibit a wide range of sizes and densities, and cannot be identified as a separate population in forward-sidewardscatter plots (Scriba et al. 1996 and unpublished observations). The low-density cell population also contains activated lymphocytes (lymphoblasts), leaving open the possibility that $\mathrm{sst}_{4}$ mRNA is up-regulated upon activation. However, we found no quantitative differences in 
Table 3 Effect of systemic administration of octreotide (as Sandostatin-LAR) on the incidence and severity of adjuvant arthritis in Lewis rats

\section{Incidence}

\begin{tabular}{|c|c|c|}
\hline Sandostatin-LAR & Controls & $P$-value** \\
\hline $7 / 9$ & $10 / 10$ & $0 \cdot 21$ \\
\hline $8 / 10$ & $7 / 10$ & $0 \cdot 50$ \\
\hline $8 / 9$ & $10 / 10$ & 0.47 \\
\hline
\end{tabular}

Severity*

\begin{tabular}{|c|c|c|}
\hline Sandostatin-LAR & Controls & $P$-value ** \\
\hline $38 \cdot 1 \pm 10 \cdot 9$ & $59 \cdot 2 \pm 14 \cdot 1$ & $0 \cdot 29$ \\
\hline $58 \cdot 3 \pm 15 \cdot 0$ & $57 \cdot 4 \pm 12 \cdot 4$ & $0 \cdot 97$ \\
\hline $105 \cdot 0 \pm 18 \cdot 3$ & $116 \cdot 3 \pm 10 \cdot 2$ & $0 \cdot 81$ \\
\hline
\end{tabular}

Octreotide dose $(\mathrm{mg} / \mathrm{kg})$

10 (experiment 1)

10 (experiment 2)

30 (experiment 3)

* Severity expressed as mean maximal increase in total paw diameter (in $0.1 \mathrm{~mm}$ ) \pm S.E.M.

**Statistics: incidence was compared using a Fisher exact test. Severity was compared using a Mann-Whitney test (two-sided).

sst subtype mRNA levels between CFA-injected rats with adjuvant arthritis and control rats. This observation again seems in contrast with the situation in the human immune system in which binding sites for somatostatin seem to be preferentially expressed on activated leukocytes (Van Hagen et al. 1994a).

Our results on the sst subtype expression in rat splenocytes contrast with the expression patterns found by others in intact rat spleen. Raulf et al. (1994) detected sst 3 mRNA but not sst $_{4}$ mRNA in rat spleen and lymph nodes. These authors also found a weak sst ${ }_{5}$ signal in the spleen. However, this expression might be due to the presence of stromal cells, e.g. nerves, which are largely eliminated in our procedure of making cell suspensions. Using a highly sensitive nuclease protection assay, Bruno et al. (1993) found mRNA for all five sst subtypes in rat spleen. It was clear from their results also that $\mathrm{sst}_{3}$ was the main subtype in spleen, whereas the other four subtypes showed much lower expression. Our results on the sst subtype expression in rat thymocytes contrast with the findings of Sedqi et al. (1996), who showed transcripts for sst $_{2}$ in resting and activated thymocytes and sst $_{1}$ in activated thymocytes, but who did not detect mRNA for sst $_{3}$. A contributing factor to the major discrepancy in sst $_{2}$ expression reported in the two papers could be the fact that Sedqi et al. analysed cells from male rats, whereas we used female rats on account of their susceptibility to adjuvant arthritis. It is known that the expression of $s t_{2}$ can be influenced by oestrogens, e.g. the transplantable rat prolactin-secreting pituitary tumour $7315 b$ expresses $s^{2} t_{2}$ when grown in vitro, but loses this expression when grown in vivo under the influence of circulating oestrogens (Visser-Wisselaar et al. 1997). However, the difference in expression of $\mathrm{sst}_{3}$ as determined in the study of Sedqi et al. and in this study needs further investigation.

At the protein level, no binding of the $s_{2}{ }_{2}$ and $\mathrm{sst}_{5}$-selective radioligand $\left[{ }^{125} \mathrm{I}_{-} \mathrm{Tyr}^{3}\right]$-octreotide was found. This result was in accordance with the lack of sst $t_{2}$ and sst $t_{5}$ expression, as found by RT-PCR. Other studies have generally found a good correlation between the presence of octreotide binding sites and the presence of sst $_{2}$ and/or sst ${ }_{5}$ mRNA (Reubi et al. 1996). The radioligand $\left[{ }^{125} \mathrm{I}_{-} \mathrm{Tyr}^{0}\right]-$ somatostatin-28 was bound, demonstrating the presence of other subtypes of sst. We therefore conclude that the mRNA for $\mathrm{sst}_{3}$ and $\mathrm{sst}_{4}$, which was detected by RT-PCR, is functional, and can give rise to membrane expression of sst proteins in rat leukocytes.

Finally, no therapeutic effect of systemic administration of octreotide, in the form of Sandostatin-LAR, was found on the incidence and severity of adjuvant arthritis in Lewis rats. This may be due to the absence in the immune system of the rat of $s t_{2}$ and $s s t_{5}$, which have a high affinity for this octapeptide somatostatin analogue. The absence of octreotide binding sites in vitro is correlated with the absence of in vivo biochemical response to octreotide, at least in the case of hormone-secreting tumours (Reubi et al. 1990). Using a different somatostatin analogue, BIM23014 $(1 \mu \mathrm{g} / \mathrm{h}$; the doses we used correspond to 2.5 and $7.5 \mu \mathrm{g}$ octreotide/h), Rees et al. (1989) did find a statistically significant decrease in arthritis severity, although a different measure of severity was used. The effect cannot be explained by differences in binding profiles of octreotide and BIM23014 (Shimon et al. 1997) on the distinct sst subtypes (although to our knowledge no comparisons of the binding profiles of these compounds on the rat sst subtypes are available). Alternatively, the somatostatin analogues might not have acted directly on the immune cells in these studies, but might have had a more generalised effect through neuroendocrine mechanisms. However, no differences were found in the efficacies of octreotide and BIM23014 in inhibiting the release of several hormones (Hofland et al. 1997, Shimon et al. 1997).

In human rheumatoid arthritis the inflamed joints may be visualised by in vivo scintigraphy using the sst $_{2}-$ and sst $_{5}$-selective somatostatin analogue $\left[{ }^{111}\right.$ In-DTPA-DPhe ${ }^{1}$-octreotide (Van Hagen et al. 1994c). In rat adjuvant arthritis the affected joints could not be visualised using this analogue (Breeman et al. 1996), indicating that the cells of the inflammatory infiltrate in the joint also lack the sst subtypes ( sst $_{2}$ and sst $_{5}$ ) which have a high affinity for octreotide. We recently showed the presence of $s_{2 \mathrm{~A}}$ in endothelial cells and cells of the monocyte/macrophage lineage in human rheumatoid synovium (ten Bokum et al., unpublished observations).

In conclusion, cells of the rat immune system appear to express a spectrum of sst ( sst $_{3}$ and sst $_{4}$ ) different from that 
found in human granulomatous and autoimmune diseases (Van Hagen et al. 1994b,c). Therefore, the rat adjuvant arthritis model appears to be suitable only for studying the immunomodulatory effects of somatostatin analogues which have a high affinity for $\mathrm{sst}_{3}$ and $\mathrm{sst}_{4}$, but not for studying the immunomodulatory effects of octreotide, which has a high affinity only for $s t_{2}$ and $s t_{5}$.

\section{Acknowledgements}

We wish to thank Prof. Dr Hemmo Drexhage and Dr Jon Laman for critical reading of the manuscript, and Tar van Os for preparing the figures. This work was supported by the Dutch Organisation for Scientific Research (NWO) (grant 903-43-092).

\section{References}

Bakker WH, Krenning EP, Breeman WAP, Koper JW, Kooy PPM, Reubi JC, Klijn JG, Visser TJ, Docter R \& Lamberts SWJ 1990 Receptor scintigraphy with a radioiodinated somatostatin analogue: radiolabeling, purification, biological activity and in vivo applications in animals. Journal of Nuclear Medicine 31 1501-1509.

Brazeau P 1986 Somatostatin: a peptide with unexpected physiologic activities. American Journal of Medicine 81 (Suppl 6B) 8-13.

Breeman WAP, van Hagen PM, Visser-Wisselaar HA, van der Pluijm ME, Koper JW, Setyono-Han B, Bakker WH, Kwekkeboom DJ, Hazenberg MP, Lamberts SWJ, Visser TJ \& Krenning EP 1996 In vitro and in vivo studies of substance $\mathrm{P}$ receptor expression in rats with the new analogue [indium-111-DTPA-Arg1]-substance P. Journal of Nuclear Medicine 37 108-117.

Bruno JF, Xu Y, Song J \& Berelowitz M 1992 Molecular cloning and functional expression of a brain-specific somatostatin receptor. Proceedings of the National Academy of Sciences of the USA 89 11151-11155.

Bruno JF, Xu Y, Song J \& Berelowitz M 1993 Tissue distribution of somatostatin receptor subtype messenger ribonucleic acid in the rat. Endocrinology 133 2561-2567.

Coari G, di Franco M, Iagnocco A, di Novi MR, Mauceri MT \& Ciocci A 1995 Intra-articular somatostatin 14 reduces synovial thickness in rheumatoid arthritis: an ultrasonographic study. International Journal of Clinical Pharmacology Research 15 27-32.

Elliott DE, Metwali A, Blum AM, Sandor M, Lynch R \& Weinstock JV 1994 T lymphocytes isolated from the hepatic granulomas of Schistosome-infected mice express somatostatin receptor subtype II (SSTR2) messenger RNA. Journal of Immunology 153 1180-1186.

Hofland LJ, de Herder WW, Visser-Wisselaar HA, van Uffelen C, Waaijers M, Zuyderwijk J, Uitterlinden P, Kros MJM, van Koetsveld PM \& Lamberts SWJ 1997 Dissociation between the effects of somatostatin (SS) and octapeptide SS-analogs on hormone release in a small subgroup of pituitary- and islet cell tumors. Journal of Clinical Endocrinology and Metabolism 82 3011-3018.

Kincy-Cain T \& Bost KL 1997 Substance P-induced IL-12 production by murine macrophages. Journal of Immunology 158 2334-2339.

Kleinau S, Dencker L \& Klareskog L 1995 Oil-induced arthritis in DA rats: tissue distribution of arthritogenic ${ }^{14} \mathrm{C}$-labelled hexadecane. International Journal of Immunopharmacology 17 393-401.

Kluxen FW, Bruns C \& Lubbert H 1992 Expression cloning of a rat brain somatostatin receptor cDNA. Proceedings of the National Academy of Sciences of the USA $894618-4622$.
Koning H, Baert MRM, de Groot R, Neijens HJ \& Savelkoul HFJ 1995 Analysis of cytokine expression in stimulated T cells of small children by semi-quantitative PCR. Mediators of Inflammation 4 194-204.

Kubota A, Yamada Y, Kagimoto S, Shimatsu A, Imamura M, Tsuda K, Imura H, Seino S \& Seino Y 1994 Identification of somatostatin receptor subtypes and an implication for the efficacy of somatostatin analogue SMS 201-995 in treatment of human endocrine tumors. Journal of Clinical Investigations 93 1321-1325.

Li XJ, Forte M, North RA, Ross CA \& Snyder SH 1992 Cloning and expression of a rat somatostatin receptor enriched in brain. Journal of Biological Chemistry 267 21307-21312.

Meyerhof W, Paust HJ, Schonrock C \& Richter D 1991 Cloning of a cDNA encoding a novel putative G-protein-coupled receptor expressed in specific rat brain regions. DNA and Cell Biology 10 689-694.

Meyerhof W, Wulfsen I, Schonrock C, Fehr S \& Richter D 1992 Molecular cloning of a somatostatin-28 receptor and comparison of its expression pattern with that of a somatostatin-14 receptor in rat brain. Proceedings of the National Academy of Sciences of the USA $\mathbf{8 9}$ 10267-10271.

Raulf F, Perez J, Hoyer D \& Bruns C 1994 Differential expression of five somatostatin receptor subtypes, SSTR1-5, in the CNS and peripheral tissue. Digestion 55 (Suppl 3) 46-53.

Rees RG, Eckland DJA, Lightman SL \& Brewerton DA 1989 The effects of somatostatin analogue, BM23014, on adjuvant arthritis in rats. British Journal of Rheumatology 28 (Suppl 2) 40.

Reichlin S 1983 Somatostatin. New England Journal of Medicine 309 1495-1501, 1556-1563.

Reubi JC 1985 New specific radioligand for one subpopulation of brain somatostatin receptors. Life Sciences 36 1829-1836.

Reubi JC, Kvols LK, Waser B, Nagorney DM, Heitz PU, Charboneau JW, Reading CC \& Moertel C 1990 Detection of somatostatin receptors in surgical and percutaneous needle biopsy samples of carcinoids and islet cell carcinomas. Cancer Research $\mathbf{5 0}$ 5969-5977.

Reubi JC, Waser B, Markusse HM, Krenning EP, van Hagen PM \& Laissue JA 1994 Vascular somatostatin receptors in synovium from patients with rheumatoid arthritis. European Journal of Pharmacology 271 371-378.

Reubi JC, Schaer J-C, Laissue JA \& Waser B 1996 Somatostatin receptors and their subtypes in human tumors and in peritumoral vessels. Metabolism 45 (Suppl 1) 39-41.

Scriba A, Luciano L \& Steiniger B 1996 High-yield purification of rat monocytes by combined density gradient and immunomagnetic separation. Journal of Immunological Methods 189 203-216.

Sedqi M, Roy S, Mohanraj D, Ramakrishnan S \& Loh HH 1996 Activation of rat thymocytes selectively upregulates the expression of somatostatin receptor subtype-1. Biochemistry and Molecular Biology International 38 103-112.

Shimon J, Taylor JE, Dong JZ, Bitonte RA, Kim S, Morgan B, Coy DH, Culler MD \& Melmed S 1997 Somatostatin receptor subtype specificity in human fetal pituitary cultures. Differential role of SSTR 2 and SSTR 5 for growth hormone, thyroid-stimulating hormone, and prolactin regulation. Journal of Clinical Investigations 99 789-798.

Tan S \& Weis J 1992 Development of a sensitive reverse transcriptase PCR assay, RT-PCR, utilizing rapid cycle times. PCR Methods and Applications 2 137-143.

Van Arman CG 1976 Pathway to adjuvant arthritis. Federation Proceedings 35 2442-2446.

Van Hagen PM, Krenning EP, Kwekkeboom DJ, Reubi JC, van den Anker-Lugtenburg PJ, Lowenberg B \& Lamberts SWJ 1994a Somatostatin and the immune and haematopoietic system; a review. European Journal of Clinical Investigation 24 91-99. 
Van Hagen PM, Krenning EP, Reubi JC, Kwekkeboom DJ, Bakker WH, Mulder AH, Laissue I, Hoogsteden HC \& Lamberts SWJ $1994 b$ Somatostatin analogue scintigraphy in granulomatous diseases. European Journal of Nuclear Medicine 21 497-502.

Van Hagen PM, Markusse HM, Lamberts SWJ, Kwekkeboom DJ, Reubi JC \& Krenning EP 1994c Somatostatin receptor imaging. The presence of somatostatin receptors in rheumatoid arthritis. Arthritis and Rheumatism 37 1521-1527.

Vernon-Roberts B, Liyanage SP \& Currey HL 1976 Adjuvant arthritis in the rat. Distribution of fluorescent material after footpad injection of rhodamine-labelled tubercle bacilli. Annals of the Rheumatic Diseases 35 389-397.

Vidal C, Rauly I, Zeggari M, Delesque N, Esteve JP, Saint-Laurent N, Vaysse N \& Susini C 1994 Up-regulation of somatostatin receptors by epidermal growth factor and gastrin in pancreatic cancer cells. Molecular Pharmacology 46 97-104.

Visser-Wisselaar HA, van Uffelen CJC, van Koetsveld PM, Lichtenauer-Kaligis EG, Waaijers AM, Uitterlinde P, Mooy DM, Lamberts SWJ \& Hofland LJ 1997 17ß-estradiol dependent regulation of somatostatin receptor subtype expression in the $7315 b$ prolactin secreting rat pituitary tumour in vivo and in vitro. Endocrinology 138 1180-1189.

Wauben MHM, Wagenaar-Hilbers JPA \& van Eden W 1994 Adjuvant arthritis. In Autoimmune Disease Models: a Guidebook, pp 201-216. Eds B Cohen \& A Miller. San Diego: Academic Press.

Wulfsen I, Meyerhof W, Fehr S \& Richter D 1993 Expression patterns of rat somatostatin receptor genes in pre- and postnatal brain and pituitary. Journal of Neurochemistry 61 1549-1552.

Yasuda K, Rens-Domiano S, Breder CD, Law SF, Saper CB, Reisine T \& Bell GI 1992 Cloning of a novel somatostatin receptor, SSTR3, coupled to adenylylcyclase. Journal of Biological Chemistry $26720422-20428$.

Received 19 February 1998

Revised manuscript received 9 June 1998

Accepted 20 November 1998 